\title{
Effect of calcitonin on gastric emptying in patients with an active duodenal ulcer
}

\author{
K JONDERKO \\ From the Department of Gastroenterology, Silesian School of Medicine, Katowice, Poland
}

SUMMARY In a double blind placebo controlled study the effect of calcitonin on gastric emptying and on serum concentrations of gastrin, insulin, glucose, calcium and phosphorus after a mixed solid-liquid meal was examined in eight patients with duodenal ulcer. Synthetic salmon calcitonin $415 \mathrm{pmol}$ iv was given as a bolus followed by a 90 minute infusion to reach an overall dose of $62.25 \mathrm{pmol} / \mathrm{kg}$. Gastric emptying of a radiolabelled meal was measured with a gamma camera. Calcitonin markedly delayed gastric emptying in all patients examined. The emptying index (Ix) decreased from $2.979(0.397) / \mathrm{min}$ after placebo to $0.896(0 \cdot 317) / \mathrm{min}$ after calcitonin $(\mathrm{p}<0.001)$. Calcitonin did not affect significantly postprandial gastrin release: $A \mathrm{UC}_{0-90}, 8768(880) \mathrm{pg} / \mathrm{l} \mathrm{min}$ (placebo) and 7807 (619) $\mathrm{pg} / \mathrm{l}$ min (calcitonin). Postprandial insulin release was abolished by calcitonin - Auc $_{0-90}, 2258$ (242) $\mathrm{mU} / / \mathrm{min}$ (placebo) v 736 (131) $\mathrm{mU} / \mathrm{l} \mathrm{min}$ (calcitonin), $\mathrm{p}<0 \cdot 001$. Parallel to the suppression of insulin release was a steady increase in the serum glucose during calcitonin infusion, with the highest glucose concentration of $5.8(0.53) \mathrm{mmol} / \mathrm{l}$ at the end of infusion of the hormone. Calcitonin did not change significantly serum calcium or phosphorus concentrations. A combination of a delaying effect on gastric emptying with the inhibition of gastric acid secretion elicited by calcitonin warrants further studies of calcinonin in the treatment of duodenal ulcer.

A search for drugs effective in the treatment of peptic ulcer has continued for decades. Attention was recently focused on the anti-ulcerogenic properties of calcitonin.' 2 Doepfner and Briner ${ }^{1}$ showed in an animal study that peripherally administered calcitonin inhibited gastric acid secretion and at the same time prevented formation of pentagastrin or histamine induced ulcers of the gastroduodenal region. An inhibition of the development of experimental ulcers was also shown after intracerebroventricular administration of calcitonin in rats. ${ }^{2}$

Our investigations showed that calcitonin markedly delayed gastric emptying in normal men. ${ }^{3}$ Hypersecretion of acid and an enhanced gastric emptying are believed to be involved in the pathogenesis of duodenal ulcer. ${ }^{\text {th }}$ Taking into account the calcitonin effects quoted above, it could be argued that calcitonin could counteract both abnormalities. The pre-

Address for correspondence: Krzysztof Jonderko, MD. Department of Gastroenterology, Silesian School of Medicine. ul Medyków 12, PL-4()-752 Katowice 6. Poland.

Accepted for publication 30 September 1988 . sent investigations were undertaken to examine the effect of calcitonin on gastric emptying, and on the profiles of serum gastrin and insulin, as well as glucose, calcium, and phosphorus concentrations after ingestion of a mixed solid-liquid meal in patients with an active duodenal ulcer.

Methods

PATIENTS

Eight male inpatients with a recent endoscopic diagnosis - that is, one established one to three days before the gastric emptying examinations - of a nonobstructing duodenal bulb ulcer participated in the study. All were habitual smokers, and smoked a median number of 15 cigarettes (range 8-20) a day for a median period of 12 years (range 3-30). Their mean values of age, weight, and height were: $35 \cdot 8$ years (range 22-55), 67.6 kg (range 60-83), and 173 $\mathrm{cm}$ (range 166-183), respectively. The median ulcer diameter was $1.0 \mathrm{~cm}$ (range $0.5-1.0$ ), whereas the median reported disease duration was four years 
(range 1-7). Physical examination and routine laboratory tests excluded other organic diseases in every participant. Specifically, among the exclusion criteria were: an endoscopic finding of bleeding or concomitant pathology within the oesophagus or stomach, history of previous gastric surgery or vagotomy, and diabetes mellitus. The patients received no medication at least three days before, or throughout the entire experimental period. Written informed consent was obtained and the study was approved by the Human Research Ethics Committee of the Silesian School of Medicine.

STUDY DESIGN AND ANALYTICAL METHODS The patients refrained from smoking and fasted overnight before the examinations. A test meal of $1650 \mathrm{~kJ}$ consisting of ${ }^{\omega_{\mathrm{m}} \mathrm{Tc}} \mathrm{Tc}$-diethylenetriaminopentaacetic acid (DTPA) labelled scrambled eggs, ${ }^{n-4}$ white bread and $250 \mathrm{ml}$ skimmed milk was given to the patients in the morning. The time needed to consume the meal did not exceed five minutes. With the $7.4 \mathrm{Mbq}$ of ${ }^{9{ }^{m} \mathrm{~T}} \mathrm{Tc}$ activity used per examination, the estimated whole body irradiation amounted to $3 \cdot 6 \cdot 10^{-5} \mathrm{~Gy}$. The meal contained $19 \cdot 3 \mathrm{~g}$ protein, $14.8 \mathrm{~g}$ fat, and $41.2 \mathrm{~g}$ carbohydrates; protein, fat, and carbohydrates supplied $20 \cdot 6 \%, 35.5 \%$, and $43.9 \%$ of the energy content of the meal, respectively. Complex carbohydrates (starch) accounted for about $70 \%$ of the carbohydrate component of the meal. The examinations were done twice on each patient, at a median interval of two days (range one to five days). Immediately after ingestion of the meal, a placebo (normal saline) or synthetic salmon calcitonin (Calsyn ${ }^{\circledR}$, Laboratoire Armour Montagu, France) was administered through an indwelling intravenous cannula inserted in the patient's antecubital fossa-a 415 pmol calcitonin bolus injection was followed by a continuous infusion for 90 minutes to reach an overall dose of $62.25 \mathrm{pmol} / \mathrm{kg}$ body mass (infusion pump type 680 , MEDIPAN, Poland). The examinations were performed in random order according to a double blind study protocol.

Blood samples were taken from the antecubital vein of the patient's other arm. Blood samples were obtained before the meal (the basal sampling designated as the time ' -5 ' minutes), just after ingestion of the meal but before the onset of calcitonin administration (the ' $\mathrm{O}$ ' time), and 30,60 , and 90 minutes after the start of calcitonin (or placebo) infusion. Serum was separated by centrifugation and kept frozen at $-20^{\circ} \mathrm{C}$ until assayed. Serum calcium and inorganic phosphorus concentrations were determined spectrophotometrically according to the procedure developed by Abbott (Abbott Laboratories Diagnostics Division USA), and serum glucose was measured by a Cormay direct glucose oxidase method. Serum insulin and gastrin concentrations were determined radioimmunologically with the use of commercially available kits: RIA-INS for insulin (code MJ-96, Isotope Production and Reactor Centre, Swierk, Poland), and Gastrin Kit (code 10994, Biodata, Italy). The sensivity of the kits was not worse than $2.5 \mathrm{mU} / \mathrm{l}$ insulin, and $10 \mathrm{ng} / \mathrm{l}$ gastrin, respectively.

GASTRIC EMPTYING MEASUREMENT AND QUANTIFICATION

As previously reported, data acquisition started immediately after meal completion. ${ }^{\prime r 4}$. Forty five two minute counts were registered with a patient sitting immobile in front of a gamma camera coupled on line with a computer device (MB 9100, Gamma Müvek Budapest, Hungary). A parallel hole high resolution collimator was used. The analyser was set on the 140 $\mathrm{keV}$ photopeak with a $20 \%$ energy window width. Quantitative analysis of the stored data was done as follows. A whole stomach region of interest (ROI) was defined by means of an edge finding programme. Time activity curves from the gastric ROI were corrected for the physical decay of the isotope and normalised for the fraction of activity remaining within the stomach (considering the peak activity frame to be $1 \cdot 0$ ). Taking into account previous investigations ${ }^{7 \times}$ background correction was omitted as negligible. Correction for the spatial movement of the tracer was obviated by an experimental design considering a subject to be his own control. The emptying index 1111 was calculated according to the formula:

$$
I x=\frac{1-F_{90}}{\int_{0}^{90} F(t) d t}
$$

where:

Ix =emptying index

$F_{90}=$ fraction of the labelled meal remaining within the stomach at the end of the gastric emptying examination-that is, after 90 minutes

$F(t)=$ fraction remaining as a function of time, $t$ $\mathrm{F}(\mathrm{t}) \mathrm{dt}=$ the integrated function

Eleven paired gastric emptying examinations carried out on normal subjects for the assessment of reproducibility of the method ${ }^{12}$ yielded a coefficient of variation of $22 \cdot 6 \%$ for Ix.

Statistical analysis was carried out with the paired Student's $t$ test. Values of $\mathrm{p}<0.05$ (two-sided) were considered to be significant. All data shown in the paper represent mean (SEM) values. 

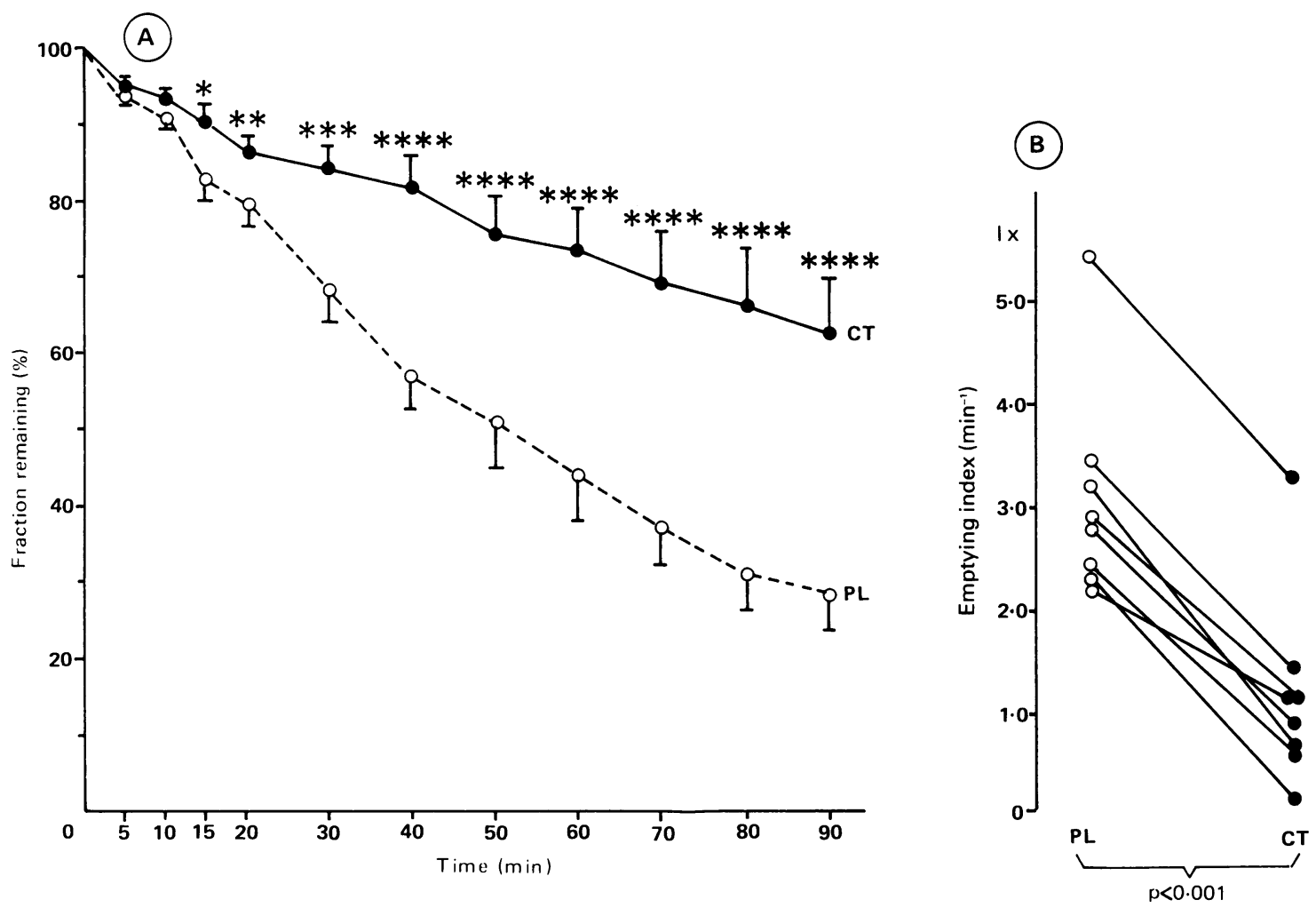

Fig. 1 Effect of calcitonin on gastric emptying of a radiolabelled solid meal in duodenal ulcer patients $(n=8)$ : (A) Plots of fraction of the meal remaining within the stomach over time-a comparison of calcitonin versus placebo: $* p<0 \cdot 05, * * p<0 \cdot 01, * * * p<0 \cdot 002, * * * * p<0 \cdot 001$, (B) Individual changes in the emptying index, Ix $(P L=p l a c e b o$, $C T=$ salmon calcitonin 415 pmol iv bolus followed by a continuous infusion during 90 minutes to reach an overall dose of $62,25 \mathrm{pmol} / \mathrm{kg}$ body mass).

\section{Results}

In all patients examined calcitonin consistently inhibited gastric emptying - a statistically significant delay in gastric emptying was observed already 15 minutes after the start, and continued till the end of calcitonin infusion (Fig. 1A). The delaying effect of calcitonin on gastric emptying was reflected by a significant decrease of the emptying index, Ix: 2.979 $(0 \cdot 397) / \mathrm{min}$. after placebo $v 0.896(0 \cdot 317) / \mathrm{min}$ after calcitonin, $\mathrm{p}<0.001$ (Fig. 1B).

The basal serum gastrin concentration amounted to $36(4 \cdot 2) \mathrm{ng} / \mathrm{l}$ on the placebo day, and $39(5 \cdot 0) \mathrm{ng} / \mathrm{l}$ on the calcitonin day-a difference statistically insignificant (Fig. 2A). Both on the placebo and on the calcitonin day, ingestion of the test meal caused a significant increase in the serum gastrin concentration (Fig. 2A). The comparison of calcitonin versus placebo at $0,30,60$, and 90 minutes revealed that the hormone did not significantly affect the postprandial release of gastrin (Fig. 2A). Thus the integrated gastrin response (the area under the gastrin curve, $\left.\mathrm{AUC}_{(2-90)}\right)$, although slightly lowered, did not significantly differ after calcitonin and after placebo administration: AUC $_{0-90} 8767$ (880) pg/l min (placebo), and 7807 (619) pg/l min (calcitonin) (Fig. 2B).

The basal serum insulin concentration did not significantly differ between the placebo $(5.4(0.65)$ $\mathrm{mU} / \mathrm{l})$ and the calcitonin $(5 \cdot 6(0.54) \mathrm{mU} / \mathrm{l})$ day (Fig. $3 \mathrm{~A})$. During the placebo infusion the serum insulin concentration significantly increased postprandially -a peak concentration of $37.5(5.73) \mathrm{mU} / \mathrm{l}$ was observed at 30 minutes after ingestion of the meal, and thereafter the serum insulin level decreased (Fig. 3A). The postprandial release of insulin was abolished during calcitonin infusion as no significant rise above the basal serum insulin concentration was observed (Fig. 3A). Consequently, the integrated insulin response was significantly suppressed after 

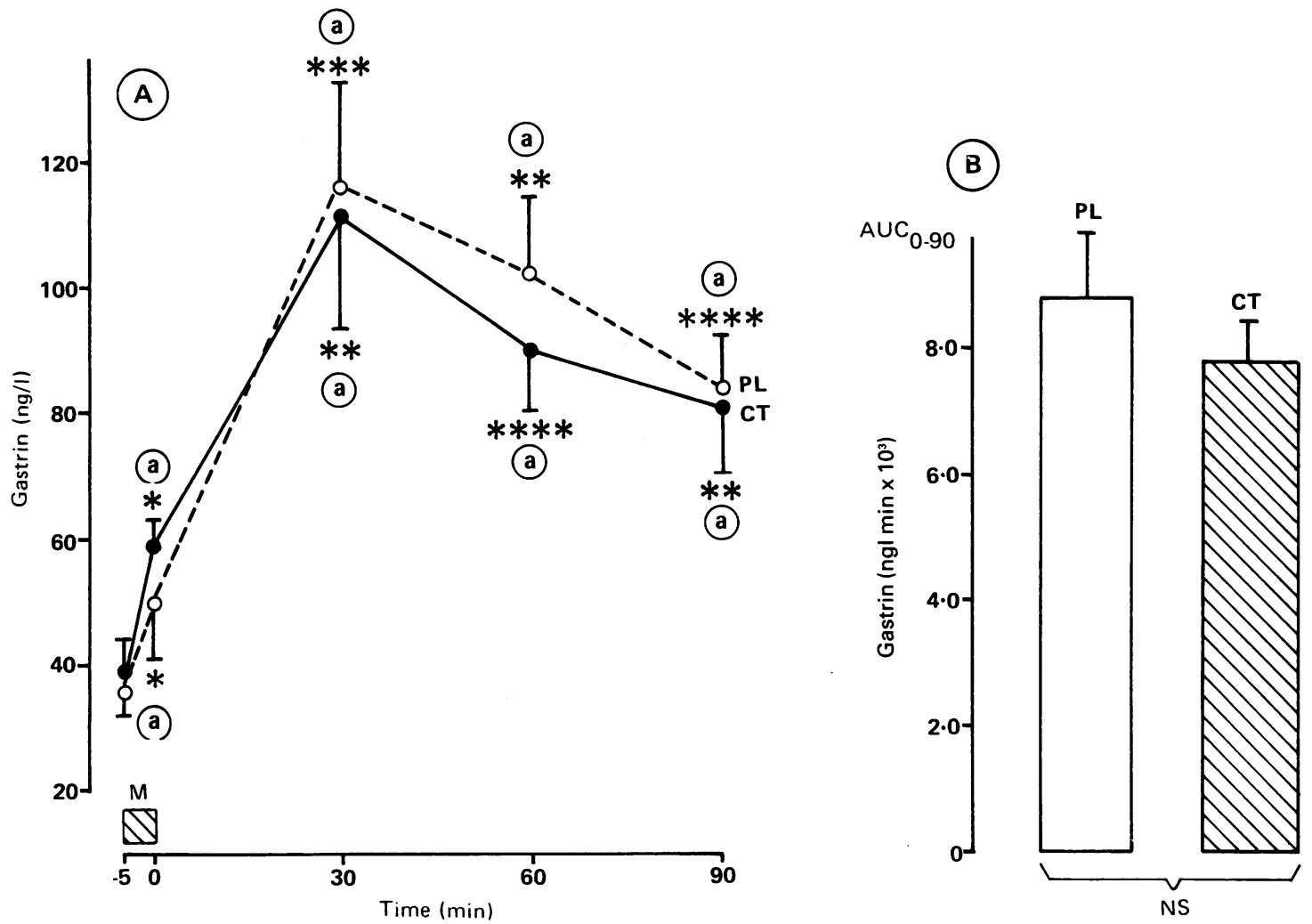

Fig. 2 Effect of calcitonin on: (A) serum gastrin concentration, and (B) on the integrated gastrin response after ingestion of a mixed solid-liquid meal in duodenal ulcer patients $(n=8)(P L=$ placebo, $C T=$ salmon calcitonin 415 pmol iv bolus followed by a continuous infusion during 90 minutes to reach an overall dose of 62.25 pmoll $\mathrm{kg}$ body mass; $(a)=$ comparison versus the basal value: $* p<0.05, * * p<0.01, * * * p<0.002, * * * * p<0.001$; comparisons of CT $v$ PL at all time points did not reveal any statistically significant differences; the moment of ingestion of the meal, $M$, indicated with a small rectangle).

calcitonin when compared with the placebo infusion: area under the insulin curve, AUC ${ }_{0-90}, 2258(242)$ $\mathrm{mU} / \mathrm{l} \mathrm{min}$ after placebo $v 736(131) \mathrm{mU} / \mathrm{l} \mathrm{min}$ after calcitonin, p $<0.001$ (Fig. 3B).

Similar basal serum glucose concentrations were found on the placebo $(3.9(0.09) \mathrm{mmol} / \mathrm{l})$ and on the calcitonin $(4.0(0.13) \mathrm{mmol} / \mathrm{l})$ day (Fig. 4). During the placebo infusion the serum glucose rose to a peak concentration of $5.4(0.45) \mathrm{mmol} / \mathrm{l}$ at 30 minutes after the test meal, and subsequently the serum glucose concentration decreased (Fig. 4). On the other hand, the serum glucose concentration steadily increased during calcitonin infusion, and statistically significant differences versus placebo were found at 60 $(\mathrm{p}<0.05)$ and $90(\mathrm{p}<0.02)$ minutes postprandially (Fig. 4).

No significant effect of calcitonin on serum concentrations of calcium or phosphorus was observed throughout the infusion when compared to the placebo situation (Fig. 5).
None of the patients reported any adverse effects during the examinations.

\section{Discussion}

According to Hotz et al ${ }^{13}$ an intravenous dose of about $41.5 \mathrm{pmol} / \mathrm{min}$ calcitonin was required to diminish gastric acid secretion in man by $50 \%$. The calcitonin dose examined in the present study provided an infusion rate of $43.8 \mathrm{pmol} / \mathrm{min}$ in a subject weighing $70 \mathrm{~kg}$. At the same time the overall administered in the present investigations calcitonin dose $(62.25 \mathrm{pmol} / \mathrm{kg}$ body mass) corresponded to an average pharmacological dose recommended for repetitive administration during a prolonged treatment in man. ${ }^{14}$

It is worth noting that a dose of calcitonin which would be expected to bring about a $50 \%$ inhibition of pentagastrin stimulated gastric acid secretion in man ${ }^{13}$ elicited a pronounced delaying effect on gastric 

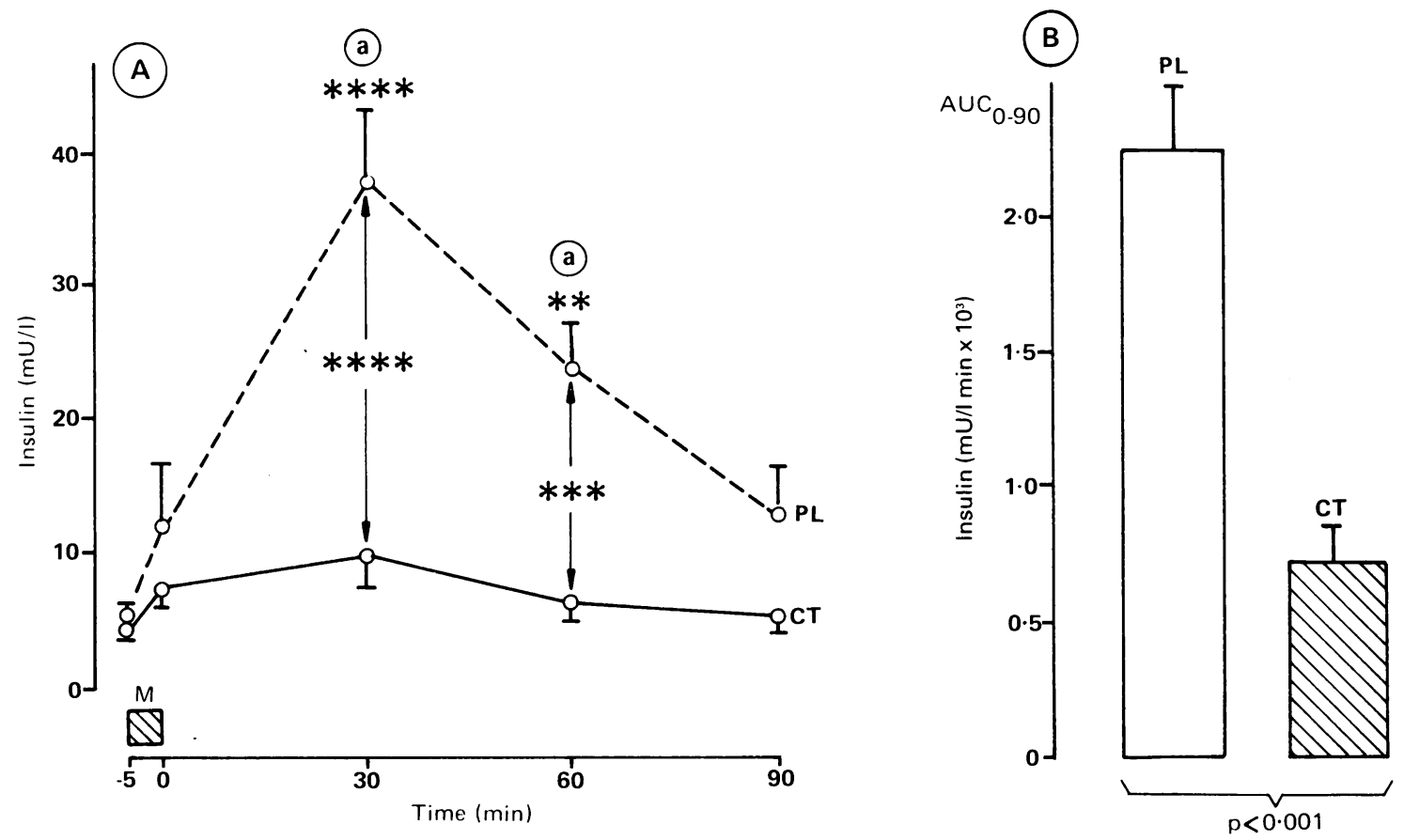

Fig. 3 Effect of calcitonin on: (A) serum insulin concentration, and (B) on the integrated insulin response after ingestion of a mixed solid-liquid meal in duodenal ulcer patients $(n=8)(P L=$ placebo, $C T=$ salmon calcitonin 415 pmol iv bolus followed by a continuous infusion during 90 minutes to reach an overall dose of $62.25 \mathrm{pmol} / \mathrm{kg}$ body mass; at the relevant time points the differences versus the basal values $(a)$, as well as $C T$ v PL were considered, $* * p<0 \cdot 005$, $* * * p<0 \cdot 002, * * * * p<0 \cdot 001$; the moment of ingestion of the meal, $M$, indicated with a small rectangle).

emptying in the patients examined. As taking into account the physiological regulatory mechanisms, an acceleration of gastric emptying would be expected to occur in response to the reduction of the acid load reaching the duodenum. ${ }^{1516}$

According to some former studies, calcitonin would be expected to decrease gastrin release. ${ }^{17} 18$ The lack of a significant inhibitory effect of calcitonin on the postprandial gastrin release, as observed in the present study, however, can be explained by the calcitonin evoked suppression of gastric emptying. Because retention of food within the stomach would elicit an augmented and prolonged gastrin release. ${ }^{16}$ Consequently, the calcitonin suppressive effect on gastrin release might be counterbalanced by a simultaneous promotion of gastrin secretion evoked secondary to the calcitonin inhibition of gastric emptying.

The results of this study indicate that suppression of the postprandial insulin release by calcitonin would be only partially explained by calcitonin inhibition of the pancreatic endocrine function. ${ }^{14} \mathrm{~A}$ factor contributing to the abolishment of release of insulin postprandially is the calcitonin evoked in- hibition of gastric emptying due to which smaller amounts of food passed into the intestine. It should be pointed out that as far as serum glucose concentration is concerned, a delaying effect of calcitonin on gastric emptying reduced the sequleae of simultaneously observed impairment of insulin release.

The results obtained indicate that calcitonin effects on the digestive tract reported here were unrelated to extracellular calcium or phosphorus concentrations. One cannot, however, exclude a possibility that calcitonin affected the intracellular distribution of calcium. ${ }^{1714}$

The present investigations showed that apart from inhibition of gastric acid secretion described by others, ${ }^{1.3}$ calcitonin markedly delayed gastric emptying in duodenal ulcer patients. Because an abnormally increased gastric emptying is met in a large subgroup of patients with an active ulcer, ${ }^{+\infty}$ it is logical to suppose that calcitonin inhibition of gastric emptying could add to ulcer healing. As calcitonin is resistant to acid and can be administered orally, ${ }^{1{ }^{13}}$ the idea of calcitonin treatment of duodenal ulcer seems to be promising and therefore a prompt performance of controlled trials should be encouraged. 

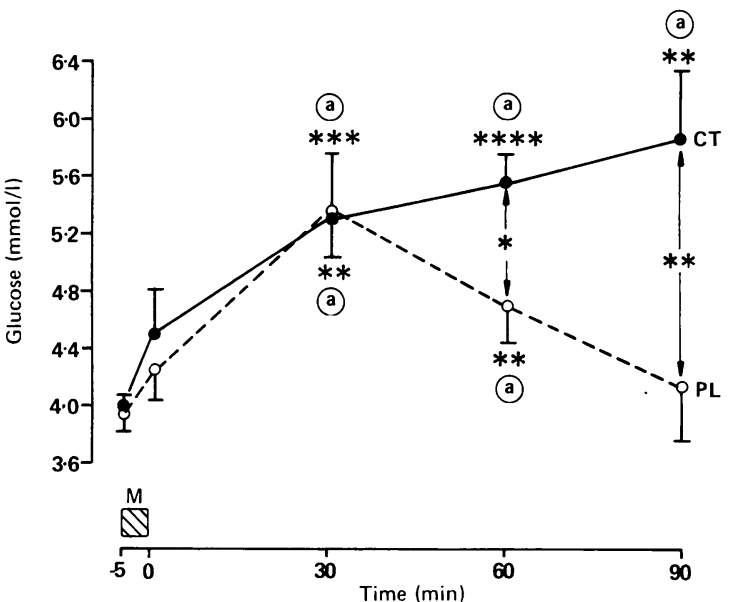

Fig. 4 Effect of calcitonin on serum glucose concentration after ingestion of a mixed solid-liquid meal in duodenal ulcer patients $(n=8)(P L=$ placebo, $C T=$ salmon calcitonin 415 pmol iv bolus followed by a continuous infusion during 90 minutes to reach an overall dose of $62.25 \mathrm{pmol} / \mathrm{kg}$ body mass; at the relevant time points the differences versus the basal values (a), as well as $C T \vee P L$ were considered, $* p<0.05$, $* * p<0 \cdot 02$, $* * * p<0 \cdot 005$, $* * * * p<0 \cdot 001$; the moment of ingestion of the meal, $M$, indicated with a small rectangle).

\section{References}

1 Doepfner W, Briner U. Hemmung der Magensekretion und der Ulkusbildung durch synthetisches Salm-Calcitonin im Tierexperiment. Triangle 1977: 16: 105-13.

2 Kauffman G, Kolve E, Hagiwara M, Tache Y. Central nervous system action of calcitonin to influence experimental gastroduodenal ulcers in rats. [Abstract]. Gastroenterology 1986; 90: 1486.

3 Jonderko G. Gołab T, Jonderko K. Effect of calcitonin on gastric emptying. Digestion 1988; 40: 191-6.

4 Lam SK, Isenberg JI, Grossman MI, Lane WH, Hogan DL. Rapid gastric emptying in duodenal ulcer patients. Dig Dis Sci 1982: 27: 598-604.

5 Jonderko K. Radionuclide studies on gastric evacuatory function in health and in the duodenal ulcer disease. I. Types of solid meal distribution within the stomach and their relation to gastric emptying. Nucl Med Commun 1987; 8: 671-80.

6 Jonderko K. Gastric emptying in active duodenal ulcer. Hepatogastroenterology 1987: 34: 272-4.

7 Jonderko K, Rudzki K, Skrzypek D. Background analysis and comparison of two solid food markers (DTPA and HSAM) in the measurement of human gastric emptying. Isotopenpraxis 1986; 22: $252-5$.

8 Jonderko K. Background does not significantly affect powerexponential fitting of gastric emptying curves. Isotopenpraxis 1987; 23: $150-2$.

9 Jonderko K. Comparison between ${ }^{\mathrm{N} m}$ Tc-DTPA and ${ }^{* m}$ Tc-human serum albumin microspheres as solid food markers in vivo. Preliminary results. Isotopenpraxis 1987: 23: 310-1.

10 Jonderko K, Kucio C, Skrzypek D. Slowed gastric evacuation accounts for the reduction of food intake by anorectics. Eur $J$ Clin Nutr 1988; 42: 627-31.

11 Jonderko K. Rudzka J, Rudzki K. Radionuclide studies on
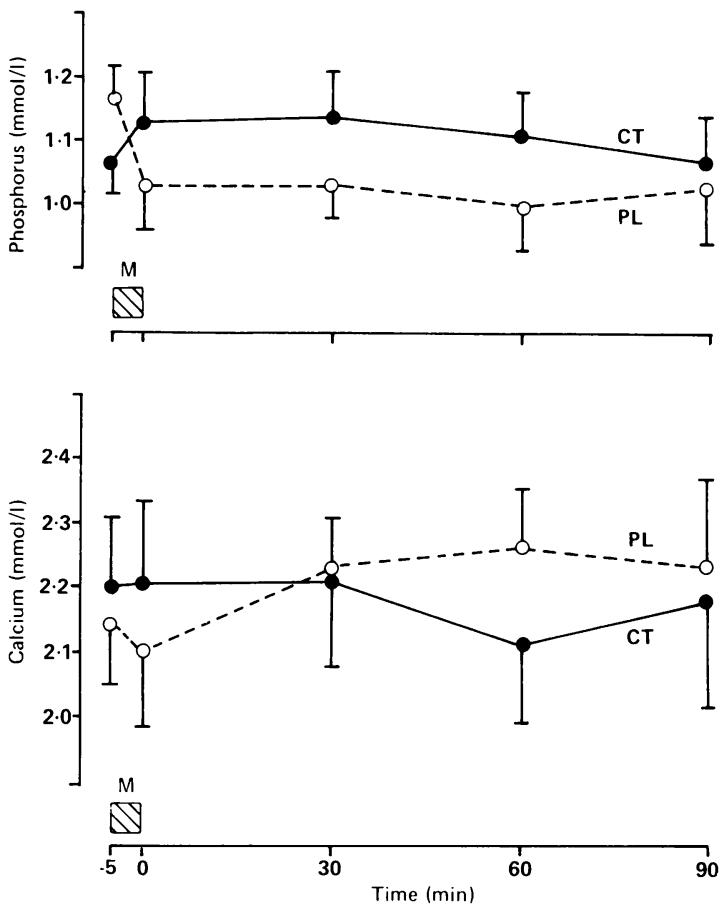

Fig. 5 Effect of calcitonin on serum calcium and phosphorus concentrations after ingestion of a mixed solid-liquid meal in duodenal ulcer patients $(n=8)$ ( $P L=$ placebo, $C T=$ salmon calcitonin 415 pmol iv bolus followed by a continuous infusion during 90 minutes to reach an overall dose of 62.25 pmoll $\mathrm{kg}$ body mass; the differences versus the basal values, as well as CTV PL at the relevant time points proved to be statistically insignificant; the moment of ingestion of the meal, $M$, indicated with a small rectangle).

gastric evacuatory function in health and in the duodenal ulcer disease. II. Regional distribution of emptying index (RDEI) patterns. Nucl Med Commun 1987, 8: 711-22.

12 Nowak A, Jonderko K, Kaczor R, Nowak S, Skrzypek D. Cigarette smoking delays gastric emptying of a radiolabelled solid food in healthy smokers. Scand J Gastroenterol 1987; 22: 54-8.

13 Hotz J, Goebbel H, Hirche H, Minne H, Ziegler R. Inhibition of human gastric secretion by intragastrically administered calcitonin. Digestion 1980; 20: 180-9.

14 Nagant de Deuxchaisnes C. Calcitonin in the treatment of Paget's disease. Triangle 1983; 22: 103-28.

15 Minami H, McCallum RW. The physiology and pathophysiology of gastric emptying in humans. Gastroenterology 1984: 86: $1592-610$.

16 Konturek SJ. Physiology of the digestive tract. Warsaw: PZWL, 1985.

17 Doepfner WEH. Pharmakologische Wirkungen von Calcitonin. Triangle 1983: 22: 57-68.

18 Chiba T, Taminato T, Kadowaki S, et al. Effects of (Asu' $)$-eel calcitonin on gastric somatostatin and gastrin release. Gut 1980; 21: $94-7$.

19 Ziegler R. Calcitonin und das endokrine Pankreas. Triangle 1983; 22: $135-45$. 